\title{
The Implication of Initial 24-Core Transrectal Prostate Biopsy Protocol on the Detection of Significant Prostate Cancer and High Grade Prostatic Intraepithelial Neoplasia
}

\author{
Michael Nomikos, Ioannis Karyotis, Prodromos Phillipou, Charalambos Constadinides, Dimitrios \\ Delakas
}

Asklepion Voula Hospital, Vasilleos Paulou 1, Athens, Greece

\begin{abstract}
Purpose: To assess the diagnostic value of an initial 24-sample transrectal ultrasound guided (TRUS) prostate biopsy protocol compared to the 10-core technique.

Materials and Methods: We retrospectively reviewed the prostate biopsy database of consecutive men undergoing prostate biopsies under local anesthesia by using the 10 (Group A) and 24 (Group B) protocols. Men were stratified according to biopsy protocol and PSA levels. Exclusion criteria were age $\geq 75$ years and PSA $>20 \mathrm{ng} / \mathrm{mL}$. The Mann-Whitney U and Fisher's exact test were used for statistical analysis.

Results: Between April 2007 and August 2009, 869 men underwent TRUS prostate biopsies of which 379 were eligible for the study. Group A (10-cores) consisted of 243 (64.11\%) men and group B (24-cores) included 139 (35.89\%) men. The overall prostate cancer detection rate was $39.09 \%$ and $34.55 \%$ in Group A and B, respectively $(p=0.43)$. An overall 9.8\% increase in Gleason 7 detection rate was found in Group B $(\mathrm{p}=0.24)$. The high-grade prostatic intraepithelial neoplasia (HGPIN) detection rate in men with negative initial biopsies was $15.54 \%$ and $35.55 \%$ in Group A and B, respectively (p $<0.001)$. In patients with PSA $<10 \mathrm{ng} / \mathrm{mL}$, the 24-core technique increased Gleason 7 detection rate by $13.4 \%(\mathrm{p}=0.16)$ and HGPIN by $23.4 \%(\mathrm{p}=0.0008)$, compared to the 10 core technique. The 24-core technique increased the concordance between needle biopsy and prostatectomy specimen compared to 10 -core technique $(\mathrm{p}<0.002)$.

Conclusions: The initial 24-core prostate biopsy protocol did not show any benefit in the detection of prostate cancer compared to the 10-core technique. However, it improved the HGPIN detection and the correlation between biopsy results and radical prostatectomy Gleason score in men with lower PSA levels.
\end{abstract}

Key words: prostatic neoplasm; biopsy; Gleason score; prostatic intraepithelial neoplasia

Int Braz J Urol. 2011; 37: 87-93

\section{INTRODUCTION}

As recommended by Hodge et al. (1), systematic transrectal ultrasound guided (TRUS) prostate biopsies is the principal method of diagnosing prostate cancer. Several studies have demonstrated that the traditional sextant technique may miss $15 \%$ - $31 \%$ of cancers and additional sampling from the peripheral zone increases the diagnostic yield of prostate biopsies (2-5). Although there is still a matter of debate regarding the optimal number of cores taken at the initial prostate biopsy, several reports have shown that extended biopsy protocols involving $>10$-cores have improved the diagnostic accuracy of clinically significant prostate cancer especially in patients with bigger glands $(6,7)$ and also improved 
the concordance of Gleason scores of needle biopsies and prostatectomy specimens (8).

The aim of the present study was to evaluate the incidence of prostate cancer, high-grade prostatic intraepithelial neoplasia (HGPIN) and perineural infiltration rates in men who had initial 24-core biopsies. The results were then compared with a similar group of men who had an initial 10-core prostate biopsy protocol. Men were categorized in different subgroups according to PSA levels. We also evaluated the ability of the initial saturation biopsy scheme to improve the prediction of the radical prostatectomy Gleason score compared to the 10-core technique.

\section{MATERIALS AND METHODS}

We retrospectively reviewed the concurrently maintained database of consecutive men who underwent TRUS prostate biopsies at one referral center. Indications for biopsy were abnormal digital rectal examination (DRE) and elevated age specific PSA levels. The 10 cores and saturation (24 cores) biopsy protocols were used as initial techniques by two staff members of the department. We used a biplane $10 \mathrm{MHz}$ transrectal probe (Pro-Focus $2202 \mathrm{TM}$,

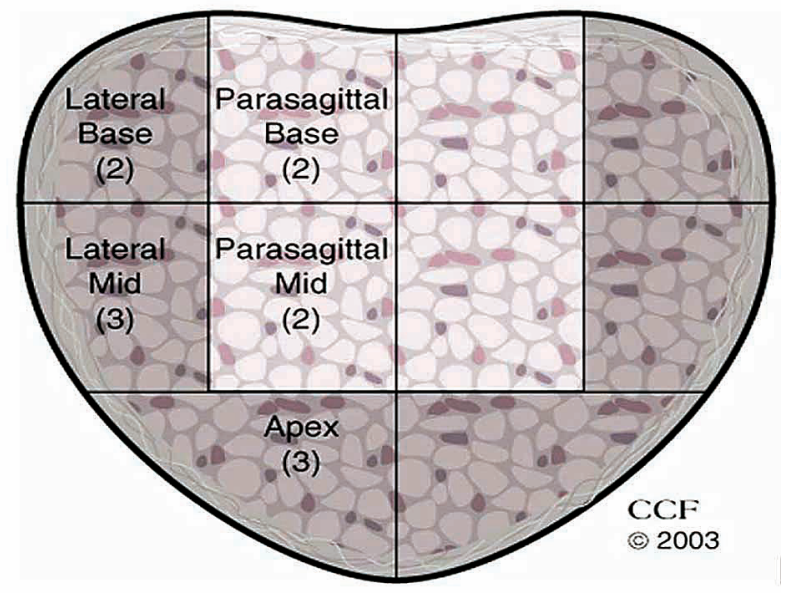

Figure 1 - Template showing location of cores obtained in 24core needle transrectal ultrasound biopsy. In the 10-core biopsy protocol, one core was obtained from each of the same sectors.
BO-Medical, Denmark) with the capability of real time three-dimensional imaging. A $20 \mathrm{~cm} 18$-gauge Chiba biopsy needle was used through a Pro-MagTM automated ultra biopsy gun (Angiotech Vancouver, BC, Canada). Prostate biopsies were done with periprostatic nerve block by using $5 \mathrm{~mL} 0.5 \%$ marcaine mixed with $5 \mathrm{~mL} \mathrm{1 \%} \mathrm{lidocaine} \mathrm{administered} \mathrm{at} \mathrm{the}$ prostate base where the prostate sensory nerves enter the gland. One dose of ciprofloxacin as standard antibiotic prophylaxis was given to all patients prior to biopsy and written informed consent was obtained from all patients.

Men were categorized in two groups according to biopsy protocol and PSA levels. For group B (24 cores), the five sectors biopsied on each side were lateral base (2), lateral mid-zone (3), apex (3), parasagittal mid-zone (2) and parasagittal base (2), as shown in Figure-1. Men in group A (10 cores), had one biopsy core obtained from each of same sectors.

Men $\geq 75$ years old, with PSA $<2.5 \mathrm{ng} / \mathrm{mL}$ and/or $>20 \mathrm{ng} / \mathrm{mL}$ and those who were previously biopsied, were excluded from analysis. Biopsy findings from both groups were compared regarding prostate cancer and HGPIN detection rates. Repeat saturation prostate biopsies were performed in 55 men from both groups with HGPIN in the initial biopsy. The concordance of Gleason score in the needle biopsy and prostatectomy specimens from both groups was also compared. Complications in both groups were recorded and compared. Results were analyzed using either the Mann-Whitney U test for continuous variables or Fisher's exact test for categorical variables.

\section{RESULTS}

Between April 2007 and August 2009, 869 men were referred for TRUS needle prostate biopsies to one referral center. Overall, 379 men (clinical stage T1c, T2), were suitable for analysis. Group A (10cores) consisted of $243(64.11 \%)$ men and group B (24-cores) included $136(35.89 \%)$ men. Both groups were comparable in terms of age, PSA and prostate volumes. Patient's demographics are summarized in Table-1.

The overall prostate cancer detection rate was $39.09 \%$ and $34.55 \%$ in Group A and B respectively 
$(\mathrm{p}=0.43)$. Table- 2 shows prostate cancer detection rates according to biopsy protocol and PSA levels. An overall 9.8\% increase in Gleason 7 score was found in Group B compared to Group A ( $\mathrm{p}=0.24)$. There was no difference in perineural infiltration rate between both groups $(\mathrm{p}=0.79)$. At a PSA range between 2.6 - $9.9 \mathrm{ng} / \mathrm{mL}$, the 24-core technique showed a non-statistically significant increase in Gleason 7 detection rate compared to the 10 -core technique $(\mathrm{p}=0.16)$. Table-3 shows Gleason score detection rates stratified according to biopsy protocol and PSA values.

The overall HGPIN detection rate in men with negative initial prostate biopsies was $15.54 \%$ and $35.55 \%$ in Group A and B, respectively $(\mathrm{p}<0.001)$. In Group B and at a PSA range between $2.6-9.9 \mathrm{ng} / \mathrm{mL}$ the overall HGPIN detection rate was increased by $23.4 \%(\mathrm{p}=0.0008)$, compared to Group A. Multifocal HGPIN detection was $8.7 \%$ and $25.4 \%$ in group A and $\mathrm{B}$, respectively $(\mathrm{p}<0.001)$. After a follow-up of 6 to 13 months, prostate cancer was subsequently detected in $8 \%$ and $74 \%$ at repeat saturation biopsies of patients with isolated and multifocal HGPIN, respectively. Table- 4 shows HGPIN detection rates at different PSA levels stratified according to biopsy protocols.

Of the subset of 62 patients from both groups who underwent radical prostatectomy and were available for analysis, $13.7 \%$ had clinically insignificant cancer (maximal tumor dimension of $1.0 \mathrm{~cm}$ or less, Gleason sum 6 or less and organ confined disease at radical prostatectomy). In men who underwent 10 core biopsies, the overall rate of Gleason score upgrading after radical prostatectomy was $42.9 \%$ compared to $26.5 \%$ if 24 cores were taken $(\mathrm{p}<0.002)$. No patients in the saturation needle biopsy group had a discrepancy of more than one Gleason unit in grade in the biopsy and surgical specimens. There were no differences in complication rates between both groups. Febrile urinary tract infections were recorded in three men from Group-B and in two men from Group A. While rectal bleeding necessitating admission was recorded in two men from Group B, there was no significant difference in patient discomfort between both groups.

Table 1 - Clinical characteristics of patients.

\begin{tabular}{lccl}
\hline \multicolumn{1}{c}{ Clinical Parameters } & $\begin{array}{c}\text { 10-Biopsy Protocol } \\
(\mathrm{N}=243)\end{array}$ & $\begin{array}{c}\text { 24-Biopsy Protocol } \\
(\mathrm{N}=136)\end{array}$ & p Value \\
\hline Age (years) & $65.4 \pm 6.4$ & $66.1 \pm 7.2$ & 0.18 \\
PSA (ng/ml) & $6.2 \pm 4.3$ & $6.2 \pm 3.9$ & 0.20 \\
Prostate volume (ml) & $42.5 \pm 5.2$ & $46.7 \pm 8.3$ & 0.16 \\
DRE $(+)$ & $21 \%$ & $8.82 \%$ & $0.028 \mathrm{NSS}$ \\
\hline
\end{tabular}

$D R E=$ digital rectal examination $;$ NSS=not statistically significant .

Table 2 - Prostate cancer detection rates according to biopsy protocol and PSA values.

\begin{tabular}{lccc}
\hline PSA $(\mathrm{ng} / \mathrm{ml})$ & \multicolumn{2}{c}{$\%$ PCa Detection } & $\begin{array}{c}\text { p Value } \\
\text { 10-Biopsy Protocol }\end{array}$ \\
& 24-Biopsy Protocol & (Fisher's exact test two-tailed) \\
\hline $2.6-9.9$ & $37.05 \%(73 / 197)$ & $33.66 \%(34 / 101)$ & 0.61 \\
$10-20$ & $47.8 \%(22 / 46)$ & $37.1 \%(13 / 35)$ & 0.37 \\
$2.6-20$ & $39.09 \%(95 / 243)$ & $34.55 \%(47 / 136)$ & 0.43 \\
\hline
\end{tabular}

PSA $=$ prostate-specific antigen 
Prostate Cancer Detection and High Grade PIN

Table 3 - Gleason score stratified according to biopsy protocol and PSA values.

\begin{tabular}{lcccccccccc}
\hline Gleason Score & \multicolumn{3}{c}{$\mathbf{6}$} & \multicolumn{3}{c}{7} & \multicolumn{3}{c}{$\mathbf{8}$} & \multicolumn{2}{c}{$\mathbf{9}$} \\
\hline Biopsy cores & 10 & & 24 & 10 & 24 & 10 & 24 & 10 & 24 \\
& & $\%$ & & & $\%$ & & $\%$ & & $\%$ & \\
$2.6-9.9 \mathrm{ng} / \mathrm{ml}$ & 49.3 & 41.2 & 21.9 & 35.3 & 4.1 & 11.8 & 8.2 & 2.9 \\
& $(36 / 73)$ & $(14 / 34)$ & $(16 / 73)$ & $(12 / 34)$ & $(3 / 73)$ & $(4 / 34)$ & $(6 / 73)$ & $(1 / 34)$ \\
$10-20 \mathrm{ng} / \mathrm{ml}$ & 63.6 & 46.15 & 59.0 & 53.8 & 18.2 & 15.4 & 9.0 & 7.7 \\
& $(14 / 22)$ & $(6 / 13)$ & $(13 / 22)$ & $(7 / 13)$ & $(4 / 22)$ & $(2 / 13)$ & $(2 / 22)$ & $(1 / 13)$ \\
\hline
\end{tabular}

PSA = prostate-specific antigen.

Table 4 - High-grade prostatic intraepithelial neoplasia (HGPIN) detection rates in biopsy negative patients stratified according to biopsy protocol and PSA values.

\begin{tabular}{|c|c|c|c|}
\hline \multirow{2}{*}{ PSA (ng/ml) } & \multicolumn{2}{|c|}{ \% HGPIN Detection } & \multirow{2}{*}{$\begin{array}{c}\text { p Value } \\
\text { (Fisher's exact } 2 \text { tailed test) }\end{array}$} \\
\hline & 10-Biopsy Protocol & 24-Biopsy Protocol & \\
\hline $2.6-9.9$ & $16.9(21 / 124)$ & $40.3(27 / 67)$ & 0.0008 \\
\hline $10-20$ & $8.33(2 / 24)$ & $21.73(5 / 23)$ & 0.24 \\
\hline
\end{tabular}

\section{COMMENTS}

Prostate cancer screening has currently increased the importance of prostate biopsy in urological practice and the detection of prostate cancer. Systemic transrectal needle biopsy of the prostate is the standard practice to detect the clinical stage and grade of disease, but controversy still exists about the optimal number of cores and the significance of HGPIN on first biopsy and how the biopsy results will improve the prediction of the prostatectomy Gleason score. In a review study, Epstein and Herawi recommended no repeat biopsies within the first year following the diagnosis of HGPIN, because the $24 \%$ median risk of prostate cancer diagnosis following detection of HGPIN was not higher than that of initial biopsy with benign disease (9). In our study, it was not the presence but the multifocality of HGPIN which was the strongest predisposing factor for detecting prostate cancer in a subsequent biopsy.
Presti (10) reviewed several studies evaluating several biopsy schemes and suggested that 10-12 core technique is optimal for most men undergoing initial prostate biopsy. Nesrallah et al. concluded that extended biopsy, with 14 cores, could improve prostate cancer detection rate compared to the sextant technique (11). Jones et al. noted, although in a small number of patients, that the 24 core technique as an initial strategy did not improve cancer detection (12).

While many studies show that saturation biopsy improves prostate cancer detection in patients with suspicious findings in a first negative biopsy, it does not seem to increase the cancer detection rate as an initial technique. Our findings are in agreement with these reports, as the 24 core initial biopsy technique did not improve the overall prostate cancer detection rate compared to the 10-core technique. In our study, men with PSA $<10 \mathrm{ng} / \mathrm{mL}$ who received an initial 24-core biopsy did not have a statistically significant increase in Gleason 7 detection rate when 
compared to 10 core protocol at the same PSA level. Furthermore, there was no difference in Gleason 8 and 9 detection rates between both biopsy protocols.

Scattoni et al. also showed that the 18 core technique as an initial strategy demonstrated a higher cancer detection rate, although not statistically significant, than the 12 core protocol in men with PSA $<10 \mathrm{ng} / \mathrm{mL}$, but they did not find any difference in the Gleason score (13). In a recent study, Scattoni et al. showed that both the number and site of cores have a great impact on prostate cancer detection and concluded that cancer detection rates increased with the increasing number of cores (14).

There are only few reports in the literature that address the influence of increased biopsy sampling on the detection rate of HGPIN and the cancer risk associated with it in subsequent biopsies. Epstein et al. report no relationship between the number of cores sampled and the incidence of HGPIN in needle biopsy (15).

However, Schoenfield et al. found an incidence of $22 \%$ in HGPIN on the first saturation biopsy. This finding was confirmed in our study, where the HGPIN detection rate of $35.55 \%$ in men who had initial saturation biopsies was one of the highest reported in the literature (16).

Several studies have reported varying results for the positive predictive value of HGPIN as a single finding for prostate cancer detection in subsequent biopsies $(17,18)$. In the present study, the cancer detection rate was significantly higher in patients with multifocal HGPIN in the initial biopsy, than in those with unifocal HGPIN ( $p=0.001)$. The majority of patients $(78 \%)$ with multifocal HGPIN on initial saturation biopsy were diagnosed with prostate cancer on repeat saturation biopsy, of which $11.8 \%$ had clinically insignificant cancer in prostatectomy specimens. These findings have been confirmed by other studies where multifocality of HGPIN is an independent risk factor of prostate cancer in subsequent biopsies (19).

Recently, few reports have proved that the extended prostate biopsy scheme when compared to the sextant technique, significantly improves the correlation between needle biopsy and prostatectomy Gleason score, and reduces the risk of upgrading to a worse Gleason group at prostatectomy $(20,21)$. In our study, Gleason score upgrading was significantly higher in the 10-core protocol when compared to the saturation technique. This finding is important since most prostate cancer cases are now detected at an early stage and at a low PSA level. Leite et al. also, showed that extended prostate biopsies in men with PSA $<4 \mathrm{ng} / \mathrm{mL}$ increased the accuracy in tumor volume, Gleason score and stage, when comparing with higher PSA values (22).

No difference in the detection of clinically insignificant cancer in radical prostatectomy specimens was observed between both biopsy protocols. In addition to its interesting results, the present study presents some limitations with the most obvious being that we do not know how many cancers were missed with either the 24 or 10 core technique. Thus, our study is influenced by verification bias because we cannot define the real diagnostic accuracy of our biopsy schemes. Another limitation is that this study is a retrospective audit with a non randomized design.

The present study did not show a real benefit for the saturation biopsy protocol as an initial technique for the detection of prostate cancer. However, it did show that an initial 24-core technique increased the detection of multifocal HGPIN and improved the concordance of Gleason grading between needle biopsy and radical prostatectomy specimen, which is crucial in therapeutic decision-making based on needle biopsy.

\section{CONCLUSIONS}

Our findings add to the growing evidence in the literature that an initial saturation (24-core) prostate biopsy protocol does not improve the overall cancer detection rate compared to the 10-core technique. Although 24-core prostate biopsy technique improved the sensitivity of HGPIN detection especially in men with PSA levels less than $10 \mathrm{ng} / \mathrm{mL}$, it cannot be justified as the standard initial biopsy technique. Patients with multifocal HGPIN on initial saturation biopsy certainly warrant repeat saturation biopsy since the great majority of them will be later diagnosed with prostate cancer. Given the fact of its safety profile, the 24-core prostate biopsy protocol could probably be proposed as the initial technique 
for a selected group of patients, such as younger men with lower PSA levels who are candidates for curative treatment, or younger patients who have opted for active surveillance. Further studies are certainly needed in this field.

\section{CONFLICT OF INTEREST}

None declared.

\section{REFERENCES}

1. Hodge KK, McNeal JE, Terris MK, Stamey TA: Random systematic versus directed ultrasound guided transrectal core biopsies of the prostate. J Urol. 1989; 142: 71-4; discussion 74-5.

2. Epstein JI, Walsh PC, Carter HB: Importance of posterolateral needle biopsies in the detection of prostate cancer. Urology. 2001; 57: 1112-6.

3. Epstein JI, Lecksell K, Carter HB: Prostate cancer sampled on sextant needle biopsy: significance of cancer on multiple cores from different areas of the prostate. Urology. 1999; 54: 291-4.

4. Miyake H, Sakai I, Harada K, Hara I, Eto H: Increased detection of clinically significant prostate cancer by additional sampling from the anterior lateral horns of the peripheral zone in combination with the standard sextant biopsy. Int J Urol. 2004; 11: 402-6.

5. Eskicorapci SY, Baydar DE, Akbal C, Sofikerim M, Günay M, Ekici S, et al.: An extended 10-core transrectal ultrasonography guided prostate biopsy protocol improves the detection of prostate cancer. Eur Urol. 2004; 45: 444-8; discussion 448-9.

6. Ficarra V, Novella G, Novara G, Galfano A, Pea M, Martignoni G, et al.: The potential impact of prostate volume in the planning of optimal number of cores in the systematic transperineal prostate biopsy. Eur Urol. 2005; 48: 932-7.

7. Inahara M, Suzuki H, Kojima S, Komiya A, Fukasawa $\mathrm{S}$, Imamoto T, et al.: Improved prostate cancer detection using systematic 14-core biopsy for large prostate glands with normal digital rectal examination findings. Urology. 2006; 68: 815-9.

8. San Francisco IF, DeWolf WC, Rosen S, Upton M, Olumi AF: Extended prostate needle biopsy improves concordance of Gleason grading between prostate needle biopsy and radical prostatectomy. J Urol. 2003; 169: 136-40.
9. Epstein JI, Herawi M: Prostate needle biopsies containing prostatic intraepithelial neoplasia or atypical foci suspicious for carcinoma: implications for patient care. J Urol. 2006; 175: 820-34.

10. Presti JC Jr: Prostate biopsy strategies. Nat Clin Pract Urol. 2007; 4: 505-11.

11. Nesrallah L, Nesrallah A, Antunes AA, Leite KR, Srougi M: The role of extended prostate biopsy on prostate cancer detection rate: a study performed on the bench. Int Braz J Urol. 2008; 34: 563-70; discussion 570-1.

12. Jones JS, Patel A, Schoenfield L, Rabets JC, Zippe CD, Magi-Galluzzi C: Saturation technique does not improve cancer detection as an initial prostate biopsy strategy. J Urol. 2006; 175: 485-8.

13. Scattoni V, Roscigno M, Raber M, Dehò F, Maga $T$, Zanoni M, et al.: Initial extended transrectal prostate biopsy--are more prostate cancers detected with 18 cores than with 12 cores? J Urol. 2008; 179: 1327-31; discussion 1331.

14. Scattoni V, Raber M, Abdollah F, Roscigno M, Dehò F, Angiolilli D, et al.: Biopsy schemes with the fewest cores for detecting $95 \%$ of the prostate cancers detected by a 24-core biopsy. Eur Urol. 2010; 57: 1-8.

15. Epstein JI, Potter SR: The pathological interpretation and significance of prostate needle biopsy findings: implications and current controversies. J Urol. 2001; 166: 402-10.

16. Moore CK, Karikehalli S, Nazeer T, Fisher HA, Kaufman RP Jr, Mian BM: Prognostic significance of high grade prostatic intraepithelial neoplasia and atypical small acinar proliferation in the contemporary era. J Urol. 2005; 173: 70-2.

17. Naya Y, Ayala AG, Tamboli P, Babaian RJ: Can the number of cores with high-grade prostate intraepithelial neoplasia predict cancer in men who undergo repeat biopsy? Urology. 2004; 63: 503-8.

18. Herawi M, Kahane H, Cavallo C, Epstein JI: Risk of prostate cancer on first re-biopsy within 1 year following a diagnosis of high grade prostatic intraepithelial neoplasia is related to the number of cores sampled. J Urol. 2006; 175: 121-4.

19. Schoenfield L, Jones JS, Zippe CD, Reuther AM, Klein E, Zhou M, et al.: The incidence of high-grade prostatic intraepithelial neoplasia and atypical glands suspicious for carcinoma on first-time saturation needle biopsy, and the subsequent risk of cancer. BJU Int. 2007; 99: 770-4.

20. Mian BM, Lehr DJ, Moore CK, Fisher HA, Kaufman RP Jr, Ross JS, et al.: Role of prostate biopsy schemes in accurate prediction of Gleason scores. Urology. 2006; 67: 379-83. 
21. Mallick S, Comoz F, Le Toquin S, Fouques Y, JeannePasquier C, Rousselot P, Bensadoun H: Can the prostate cancer detection rate be improved with a saturation technique of prostate biopsy? Urology 2007; 70(Suppl 1): 300-01. \# Abstract POS-03.91.
22. Leite KR, Srougi M, Dall'Oglio MF, Sanudo A, Camara-Lopes LH: Histopathological findings in extended prostate biopsy with PSA $<$ or $=4 \mathrm{ng} / \mathrm{mL}$. Int Braz J Urol. 2008; 34: 283-90; discussion 290-2.

Accepted after revision:

May 7, 2010

\section{Correspondence address:}

Dr. Michael Nomikos

Asklepion Voula Hospital

Knossou 275, Heraklion

Crete, 71409, Greece

Fax: + 3028 1036-8083

E-mail:mnomikos@gmail.com

\section{EDITORIAL COMMENT}

The search continues for the optimal number of prostate biopsies to maximize clinical utility while minimizing complications. The authors reported on a non-randomized group of 379 men who underwent transrectal prostate biopsy using either a 10 or 24core technique. No increased complications were reported with the saturation technique. The detection of prostate cancer (including Gleason grade 7) was not statistically different between the two groups while HGPIN was increased. A prior thorough review publication (1) reported a median risk recorded in the literature for cancer following the diagnosis of HGPIN on needle biopsy is $24.1 \%$, which is not much higher than the general population and recommended against rebiopsy based solely on HGPIN. The authors in the current study report improved concordance between biopsy and prostatectomy specimens when more biopsies were taken. In the face of no increased cancer detection, the urologist must balance the impact of potential increased complications, time, and patient discomfort when deciding on prostate biopsy technique.

\section{REFERENCE}

1. Epstein JI, Herawi M: Prostate needle biopsies containing prostatic intraepithelial neoplasia or atypical foci suspicious for carcinoma: implications for patient care. J Urol. 2006; 175: 820-34.

Dr. Kenneth Nepple University of Iowa Hospitals and Clinics Iowa City, Iowa, USA E-mail: kenneth-nepple@uiowa.edu 